\title{
A novel photo-respirometry method to characterize consortia in microalgae- related wastewater treatment processes
}

\author{
A. Sánchez-Zurano*, C. Gómez-Serrano, F.G. Acién-Fernández, J.M. Fernández-Sevilla, \\ E. Molina-Grima \\ Chemical Engineering Department, University of Almeria, Ctra. Sacramento, s/n, 04120 Almería, Spain
}

\section{A R T I C L E I N F O}

\section{Keywords:}

Microalgae

Bacteria

Photosynthesis

Respiration

Heterotrophic

Nitrification

\begin{abstract}
A B S T R A C T
In this paper, a new photo-respirometry method for determining the rates of the main metabolic processes of microalgae-bacteria consortia in microalgae-based wastewater treatment processes has been developed and tested. The proposed protocol consists on applying dark and light periods to a microalgae-bacteria consortium in the presence of different substrates and measuring the rate of oxygen production. This allows determining the activity of microalgae, heterotrophic bacteria and nitrifying bacteria separately.

The method has been optimized in terms of the operation strategy, including the starvation period required, the biomass concentration and the irradiance during the measurements. Results show that a starvation period of one to three days is necessary depending on the nutrient concentration. The optimal experimental conditions determined were a biomass concentration of $0.5 \mathrm{~g} / \mathrm{L}$ and an irradiance of $200 \mu \mathrm{mol}$ photons $/ \mathrm{m}^{2} \cdot \mathrm{s}$. Furthermore, microalgae-bacteria samples from seven photobioreactors (indoor and outdoor) with different nutrient sources have been evaluated applying the methodology proposed. Regardless of the wastewater type, the microalgae activity is the main metabolic process, with heterotrophic activity increasing along with the chemical oxygen demand (COD) in the wastewater. Nitrifying activity was only observed when high ammonium concentrations were present. The developed method is a powerful tool to adequately manage and operate wastewater treatment processes using microalgae/bacteria consortia, providing valuable information to model wastewater treatment systems with microalgae and determine kinetic parameters.
\end{abstract}

\section{Introduction}

The use of microalgae-bacteria consortia in multiple biotechnology processes, such as in wastewater treatment, has required an understanding of the mechanisms involved in microalgae-bacteria interaction [1]. Knowledge of the microalgae-bacteria consortia which appear in the treatment of wastewaters (from urban, industrial, agricultural and animal-use sources) is essential to maximise the benefits of microalgae wastewater treatment, as previously reported [2-4]. The schematic functioning of this consortia has been previously described. When illuminated, the microalgae consume inorganic carbon, nitrogen and phosphorus, as well as other compounds, to produce biomass while simultaneously releasing oxygen from photosynthesis [5,6]. This activity is beneficial in wastewater treatment processes because the oxygen produced by microalgae can be used by aerobic bacteria to biodegrade pollutants, so they are capable of oxidizing organic matter into inorganic compounds mainly containing nitrogen and phosphorus [7]. Moreover, the carbon dioxide produced by bacterial respiration is consumed by the microalgae, completing a photosynthesis-respiration cycle [8].

In microalgae-based wastewater treatment, it is considered that an equilibrium exists between microalgae and bacteria-related processes. However, this is not always true because, depending on the operational conditions, the prevalence of microalgae or bacteria varies greatly [9]. Accordingly, recent studies have shown that the bacterial contribution to a consortium's performance is lower than that from the microalgae; this is due to the fact that the bacteria's metabolism is faster than the microalgae's so only a low bacterial mass is necessary to degrade organic compounds into inorganic compounds. Moreover, the amount of oxygen produced in this process by the microalgae population is far higher than that required by the low bacterial mass. Consequently, the relationship between microalgae and bacteria in a consortium is determined by the wastewater composition and its feed rate. For this reason, it is essential to understand and model these phenomena so as to adequately design and operate microalgae-based systems for wastewater treatment [10].

\footnotetext{
* Corresponding author.

E-mail address: anasanchezzurano@gmail.com (A. Sánchez-Zurano).
} 
Similarly, inspired by classic respirometric techniques in the activated sludge process, some authors started to apply respirometry to study microalgae activity and to determine microalgae kinetic parameters [11-13]. Despite respirometry has been considered for years an adequate approach to rapidly determine microalgae activity, the methods applied were often ambiguous on what exact test devices are needed or test conditions. In this way, [14] developed a standard procedure to determine algal activities through specific oxygen production rate (SOPR) in the light and specific oxygen uptake rate (SOUR) in the dark, which could allow for determination of microalgae growth kinetic. Other authors have applied similar respirometry techniques in microalgae cultures but shortening the duration of the dark-light cycles to a few minutes that are sufficient to obtain enough dissolved oxygen measurements in order to estimate the influence of different environmental factors $[13,15,16]$. However, respirometry methods have been generally applied to pure microalgae cultures, while in wastewater processes is indispensable to consider the existence of microalgae-bacteria consortia. On this issue, some authors have started to develop respirometry methods for studying microalgae-bacteria consortia by evaluating both microalgae and bacterial activity, specifically nitrifying activity in microalgae wastewater treatment [17].

This work aims to develop a complete photo-respirometry method to quantify the microalgae-bacteria consortia found in wastewater treatment processes, distinguishing between microalgae, heterotrophic and nitrifying activity using the oxygen production/consumption rates. The method's operational conditions have been optimized to define a standardized protocol for characterizing this type of consortia. Furthermore, the developed method has been used to compare the composition of microalgae-bacteria consortia prevailing in different wastewater treatment processes and in pure microalgae cultures, thus showing the large variability of these types of consortia. The methodology described here is a valuable tool for optimizing any microalgaebased process, especially those related to wastewater treatment, which are expected to expand greatly in the near future.

\section{Materials and methods}

\subsection{Photosynthesis and respiration rate measurements}

A photo-respirometer device was designed and built in-house. This equipment allows to determine any variation in dissolved oxygen concentration in microalgae culture samples under controlled conditions. It comprises an $80 \mathrm{~mL}$ jacketed transparent cylindrical glass flask (connected to a temperature-controlled water reservoir for the device's temperature control), which is magnetically stirred and artificially illuminated using two power-controlled LED lamps (Secom Iluminacion 4125015085DR, Spain) placed to the right and left of the glass chamber (Fig. 1A). The light provided by the lamps can be automatically regulated to obtain the desired irradiance inside the centre of the chamber once the sample is added. The device is also equipped with a diffuser through which gases (air, $\mathrm{O}_{2}, \mathrm{~N}_{2}$ and $\mathrm{CO}_{2}$ ) can be supplied at a low flow rate to modify the culture's dissolved oxygen or $\mathrm{pH}$. To achieve this, the device is also equipped with sensors for irradiance (QSL-1000, Walz, Germany), temperature (PT-100), pH (Crison 5343, Barcelona, Spain) and dissolved oxygen (Crison 5002, Barcelona, Spain) located inside the flask.

An adequate protocol was developed to determine the microalgae cultures' photosynthesis and respiration rates. The developed methodology allows to distinguish between the metabolisms of the three main populations: the microalgae, the heterotrophic bacteria and the nitrifying bacteria. Firstly, samples of the microalgae cultures were taken and subjected to nutrient starvation (continuous light of 200 $\mu \mathrm{Em}^{-2} \mathrm{~s}^{-1}$ and an aeration rate of $0.2 \mathrm{v} \cdot \mathrm{v}^{-1} \cdot \mathrm{min}^{-1}$ ) to remove the organic matter and the ammonium present in the medium. Subsequently, the samples were placed inside the jacketed flask and the variation in dissolved oxygen over time was measured under different conditions. The temperature was controlled at $24-25^{\circ} \mathrm{C}$ in the culture. To determine the microalgae's net photosynthesis rate and the respiration rates of the heterotrophic and nitrifying bacteria, each sample was subjected to four light-dark periods of $4 \mathrm{~min}$, during which the variation in dissolved oxygen over time was measured and registered. These values allow calculating the respective metabolic rates. The first minute of exposure was disregarded as it was considered to be adaptation time.

The variation in dissolved oxygen was measured in the $90-130 \%$ Sat range (i.e., when the level of dissolved oxygen was between $90 \%$ and $130 \%$ with respect $100 \%$ that corresponds to air saturation), in which the oxygen mass transfer was determined. The entire system was computer-controlled using DaqFactory software. In the following section, each part of the process is described in detail, including the expected biological reactions affecting the dissolved oxygen concentration:

- Microalgae net photosynthesis rate (MNPR). A culture sample was placed inside the photo-respirometer and then exposed to four light-dark cycles of $4 \mathrm{~min}$ each to measure and register the variation in dissolved oxygen under every condition. Between the dark and light periods, air was provided in order to recover the $100 \%$ Sat of the dissolved oxygen. During the light periods, oxygen generation is expected as a result of the active photosynthesis in microalgae whereas during the dark periods, the oxygen is consumed by the endogenous respiration rate. Endogenous respiration is defined as the culture's oxygen consumption rate when subjected to starvation, which is indicative of the active biomass concentration [18]. The microalgae net photosynthesis rate was calculated as the difference between the slope of the oxygen production during the light period minus the slope of the oxygen consumption during the dark period.

- Heterotrophic bacteria respiration rate (HBRR). Another culture sample was used for this measurement. Now, $0.8 \mathrm{~mL}$ of sodium acetate $(30 \mathrm{~g} / \mathrm{L})$ were added as an organic matter source. Acetate has been described as a substrate for use in wastewater respirometry tests [18]. The sample was exposed to four light-dark cycles of $4 \mathrm{~min}$ each. Between each light and dark period, air was provided in order to recover the $100 \%$ Sat of the dissolved oxygen. The oxygen consumption in the dark phase allows to determine the oxygen consumed by the heterotrophic biomass. The respiration rate of the heterotrophic bacteria was calculated as the slope of the oxygen consumption with sodium acetate minus the slope of the oxygen consumption during the dark period in the endogenous culture.

- Nitrifying bacteria respiration rate (NBRR). Another sample of culture was used for this measurement. For this procedure, $0.8 \mathrm{~mL}$ of ammonium chloride $(3 \mathrm{~g} / \mathrm{L})$ was added as the ammonium source. Among the different ammonium sources that have been used to evaluate nitrifying activity in activated sludge processes and microalgae-bacteria consortia, ammonium chloride has been the most extensively utilized $[17,18]$. The sample was exposed to four light-dark cycles of $4 \mathrm{~min}$ each. In the middle of each light and dark period, air was provided in order to recover the $100 \%$ Sat of dissolved oxygen. The oxygen consumption in the dark phase allows to determine the oxygen consumed by nitrifying biomass. The nitrifying bacteria's respiration rate was calculated as the slope of the oxygen consumption with ammonium chloride minus the slope of the oxygen consumption during the dark period in the endogenous culture.

A simplified scheme of the proposed methodology is shown in Fig. 1B. During the dark phases (D1-D4), the dissolved oxygen is consumed by microalgal-bacterial endogenous respiration. During the light phase (L1-L4), the microalgae perform photosynthesis and the dissolved oxygen production increases while, simultaneously, it is consumed by the respiration processes. The microalgae net photosynthesis rate (MNPR) is calculated as the difference between the oxygen production 


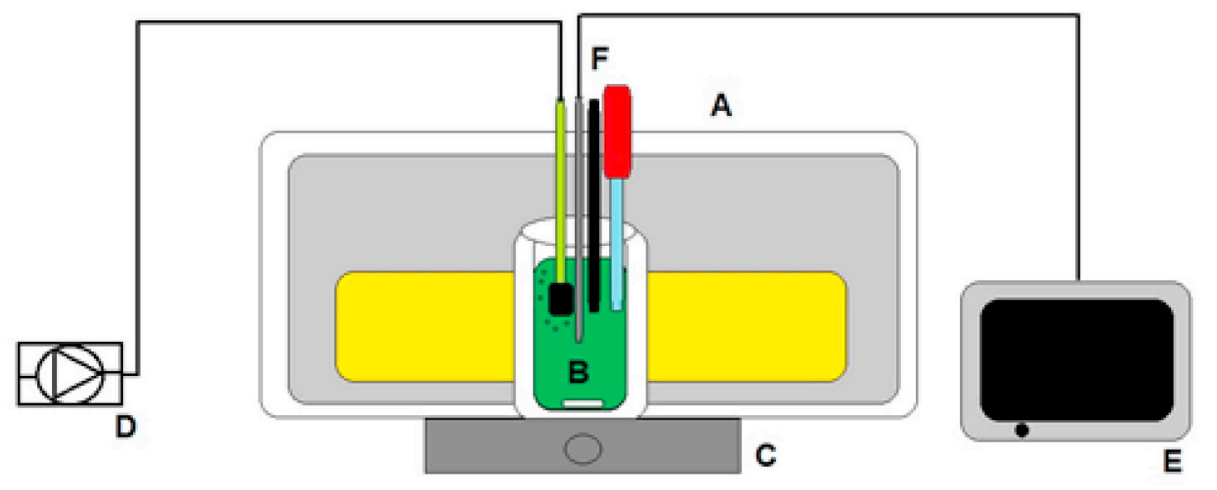

A)

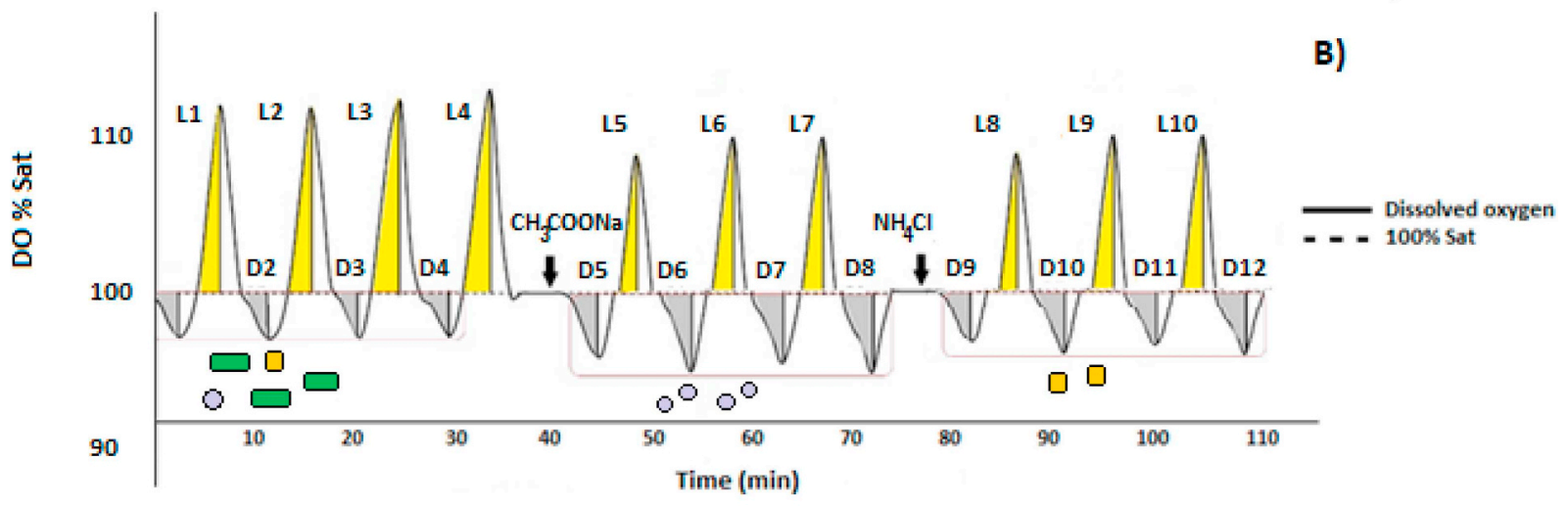

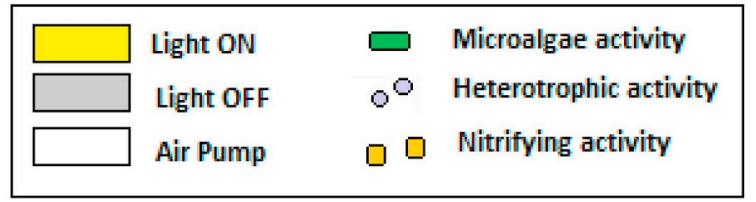

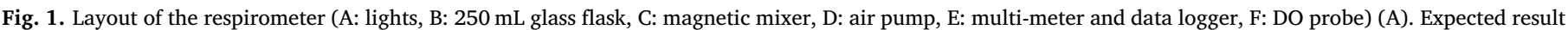

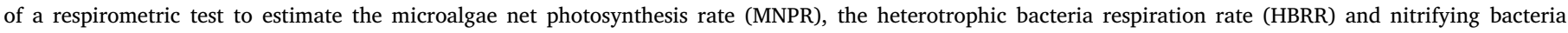

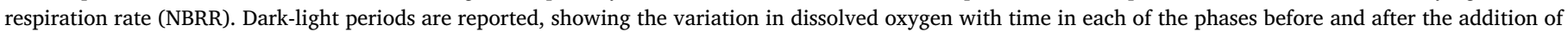
substrates which activate bacterial populations (B).

rate (OPR) during the light period minus the oxygen consumption rate (OCR) during the dark period, divided by the dry weight of total biomass (Cb) (Eq. 1).

$M N P R=\frac{O P R-O C R}{C b}$

After adding sodium acetate, the same measurements are performed to determine the heterotrophic metabolism, always starting with a new sample. During the dark phases (D5-D8), the dissolved oxygen is consumed by heterotrophic biomass. Thus, the heterotrophic bacteria respiration rate (HBRR) was calculated as the difference between the heterotrophic oxygen consumption (HOCR) rate, after providing acetate, and the oxygen consumption rate (OCR) without adding sodium acetate, divided by the dry weight of the total biomass (Eq. 2).

$H B R R=\frac{H O C R-O C R}{C b}$

Similarly, the nitrifying bacteria respiration rate (NBRR) was calculated by adding ammonia chloride as a substrate in a new sample of the culture. NBRR is determined as the difference between the nitrifying oxygen consumption (NOCR) rate after providing ammonium chloride (D9-D12) and the oxygen consumption rate (OCR) without adding ammonium chloride, divided by the dry weight of the total biomass (Eq. 3).
$N B R R=\frac{N O C R-O C R}{C b}$

Four measurement replicates of each biological activity were done.

\subsection{Oxygen mass transfer determination}

In order to correct the influence of desorption on the metabolic activity measurements, the oxygen mass transfer coefficient $\left(\boldsymbol{K}_{L} \boldsymbol{a}\right)$ in absence of aeration was determined experimentally. The method used consisted in measuring the dissolved oxygen concentration versus time profiles in the same chemical-physical conditions set during the experiments. For this, a cell-free sample was placed in the measurement device and the concentration of oxygen was increased to $130 \%$.sat by bubbling with the pure $\mathrm{O}_{2}$ gas. After this, the bubbling was stopped and the variation in oxygen concentration $\left(\boldsymbol{C}_{\boldsymbol{O} 2}\right)$ with time was monitored for around $4 \mathrm{~h}$. The $\boldsymbol{K}_{\boldsymbol{L}} \boldsymbol{a}$ in the system quantifies the proportionality between the oxygen exchange between the liquid and gas phases and the driving force expressed as $\left(\boldsymbol{C}_{\mathbf{0 2}}{ }^{*}-\boldsymbol{C}_{\boldsymbol{O} 2}\right)$ leading to the following elementary mass balance:

$\frac{d \mathrm{CO} 2}{d t}=K_{L} a\left(C_{02}^{*}-C_{O 2}\right)$

Where $\mathrm{dC}_{\mathrm{O} 2} / \mathrm{dt}$ is the oxygen accumulation expressed as the derivate of $\mathrm{C}_{\mathrm{O} 2}(\mathrm{mg} / \mathrm{L})$ over time, $\mathrm{K}_{\mathrm{L}} \mathrm{a}$ is the global oxygen mass transfer 
Table 1

Composition of the waters used as influent in the cultivation systems.

\begin{tabular}{|c|c|c|c|c|}
\hline \multirow[t]{2}{*}{ Parameters } & \multicolumn{4}{|c|}{ Cultivation systems } \\
\hline & Arnon medium & Primary domestic wastewater & Pig manure wastewater & Agricultural waste leachates \\
\hline $\mathrm{pH}$ & $7.9 \pm 0.2$ & $7.6 \pm 0.1$ & $7.7 \pm 0.0$ & - \\
\hline Conductivity, $\mathrm{mS} / \mathrm{cm}^{-1}$ & $2.3 \pm 0.1$ & $1.9 \pm 0.1$ & $17 \pm 0.2$ & - \\
\hline Turbidity, FTU & $0.0 \pm 0.0$ & $17 \pm 0.4$ & $7.3^{*} 10^{3} \pm 3.1$ & $1.9 * 10^{3} \pm 0.9$ \\
\hline SST, g/L & $0.6 \pm 0.0$ & $0.6 \pm 0.1$ & $12 \pm 0.1$ & $8.2 \pm 2.4$ \\
\hline $\mathrm{N}-\mathrm{NH}_{4}, \mathrm{mg} / \mathrm{L}$ & $0.0 \pm 0.0$ & $59 \pm 0.8$ & $2.9 * 10^{3} \pm 1.2$ & $3.9 * 10^{3} \pm 3.1$ \\
\hline $\mathrm{N}-\mathrm{NO}_{3}, \mathrm{mg} / \mathrm{L}$ & $1.4 * 10^{2} \pm 2.2$ & $2.9 \pm 0.1$ & $7.4 * 10^{2} \pm 1.2$ & $1.9 * 10^{2} \pm 2.4$ \\
\hline $\mathrm{P}-\mathrm{PO}_{4}, \mathrm{mg} / \mathrm{L}$ & $30.9 \pm 0.7$ & $11.1 \pm 0.3$ & $1.3 * 10^{2} \pm 1.5$ & $8.2 * 10^{2} \pm 1.8$ \\
\hline $\mathrm{COD}, \mathrm{mg} / \mathrm{L}$ & - & $5 * 10^{2} \pm 3.2$ & $2.2 * 10^{4} \pm 5.6$ & $3.3 * 10^{4} \pm 4.9$ \\
\hline
\end{tabular}

Data shown are the mean $\pm \operatorname{SD}(n=3)$.

coefficient $\left(\mathrm{h}^{-1}\right)$, and $\mathrm{C}_{\mathrm{O} 2} *$ is the oxygen saturation concentration in the liquid.

Eq. 4 can be rearranged as follow:

$K_{L} a \int_{0}^{t} d t=\int_{C_{O 20}}^{C_{O 2}} \frac{\mathrm{d} C_{O 2}}{C_{02}^{*}-C_{O 2}}$

Leading to

$\ln \left(\frac{C_{02}^{*}-C_{O 2 o}}{C_{02}^{*}-C_{O 2}}\right)=t \cdot K_{L} a$

This means that $\mathrm{K}_{\mathrm{L}} \mathrm{a}$ can be obtained from data of $\mathrm{C}_{\mathrm{O} 2, \mathrm{t}} \mathrm{vs}$. as the slope of the plot of $\ln \left(\frac{C_{02}^{*}-C_{020}}{C_{02}^{*}-C_{O 2}}\right)$ against time. The final value obtained was $1.08 \mathrm{~h}^{-1}$. This value was used to correct the different metabolic responses as described by [13].

\subsection{Respiration rate measurements by inhibiting nitrifying activity}

The methodology was enhanced in order to distinguish between the ammonium consumption by nitrifying bacteria and by microalgae inhibiting the nitrifying activity of the ammonia-oxidizing bacteria. For this, allylthiourea solution (ATU) $(1 \mathrm{~g} / \mathrm{L})$ was used as inhibitor, which was dosed in order to achieve ATU concentration of $10 \mathrm{mg} / \mathrm{L}$. Then, the following measurements described in detail were done.

- Firstly, a culture sample was placed inside the photo-respirometer and exposed to four light-dark cycles of $4 \mathrm{~min}$ each to measure and register the variation in dissolved oxygen under light-dark periods. During the dark periods, the oxygen is consumed by the endogenous respiration rate. The oxygen consumption rate (OCR) during the dark period was calculated as the slope of dissolved oxygen consumption during the dark period.

- Next, a fresh sample was placed in the equipment in order to determine the total ammonium respiration rate (TARR) by the culture. For this, $0.8 \mathrm{~mL}$ of ammonium chloride solution $(3 \mathrm{~g} / \mathrm{L})$ was added as nutrient source. The sample was then exposed to four light-dark cycles of $4 \mathrm{~min}$ each. The ammonium oxygen consumption rate (AOCR) in the dark phase was calculated as the slope of dissolved oxygen consumption with ammonium chloride minus the dissolved oxygen consumption during the dark period in the endogenous culture.

- Then, in order to determine the ammonium respiration due to the microalgae activity, the microalgae ammonium respiration rate (MARR) was calculated using another sample. In this measurement, ATU and ammonium chloride were added in order to inhibit ammonia oxidizing bacteria and measure the microalgae ammonium respiration. The sample was exposed to four light-dark cycles of 4 min each. The microalgae ammonium oxygen consumption rate (MAOCR) in the dark phase was calculated as the slope of dissolved oxygen consumption with ATU and ammonium chloride minus the dissolved oxygen consumption during the dark period in the endogenous culture.

The proposed protocol was used to determine the total ammonium respiration rate (TARR):

$\mathrm{TARR}=\frac{\mathrm{AOCR}-\mathrm{OCR}}{C b}$

The microalgae ammonium respiration rate (MARR):

MARR $=\frac{\text { MAOCR }- \text { OCR }}{C b}$

Thus, the nitrifying ammonium respiration rate (NARR) was calculated as the difference between the total ammonium respiration rate (TARR) rate and the microalgae ammonium respiration rate (MARR).

NARR $=$ TARR - MARR

\subsection{Microorganisms and culture conditions}

\subsubsection{Samples from laboratory culture}

The strain Scenedesmus almeriensis was used as the control microorganism. Stock cultures were maintained photo-autotrophically in spherical flasks (1.0 L capacity) using Arnon medium [19]. The culture was continuously bubbled with an air $-1 \% \mathrm{CO}_{2}$ mixture to control the $\mathrm{pH}$ at 8.0. The culture was artificially illuminated in a $12: 12 \mathrm{~h} \mathrm{~L} / \mathrm{D}$ cycle using four Philips PL-32W/840/4p white-light lamps, providing an irradiance of $750 \mu \mathrm{E} / \mathrm{m}^{2}$ s. For the experiments, this inoculum was transferred to laboratory-scale photobioreactors and industrial-scale outdoor photobioreactors. Details on the reactors and culture medium used in each experiment are given below. The average composition of the wastewaters used is reported in Table 1.

2.4.2. Samples from spherical flasks fed with Arnon medium with acetate Experiments were performed in 4 spherical flasks (1.0 L capacity) filled up to $650 \mathrm{~mL}$ with Arnon medium complemented with different acetate concentrations and $20 \%$ of Scenedesmus almeriensis inoculum. The Arnon medium, except the organic substrates, was sterilised in an autoclave at $128^{\circ} \mathrm{C}$ for $21 \mathrm{~min}$. The organic nutrient (acetate) was separately sterilised by filtration through $0.2 \mu \mathrm{m}$ pore membranes. The reactors were operated in batch mode for $96 \mathrm{~h}$. The nutrient concentrations used were $0.005,0.01$ and $0.05 \mathrm{M}$, and a photoautotrophic control. Each reactor was aerated at a rate of $0.2 \mathrm{v} / \mathrm{v} / \mathrm{min}$, with $\mathrm{CO}_{2}$ injected on demand $(\mathrm{pH}=8)$. The reactors were artificially illuminated continuously using eight $28 \mathrm{~W}$ fluorescent tubes (Philips Daylight T5). The temperature was kept at $25^{\circ} \mathrm{C}$.

\subsubsection{Samples from bubble columns fed with crop residue leachate}

Experiments were performed in 12 bubble column-type reactors with spherical bases $(3 \mathrm{~cm}$ in diameter, $45 \mathrm{~cm}$ in height and with a $300 \mathrm{~mL}$ capacity) filled up to $250 \mathrm{~mL}$ with leachate from crop residues diluted in water (10\% crop residues, $90 \%$ water) and $20 \%$ of 
Scenedesmus almeriensis inoculum. Each reactor was aerated at a rate of $0.2 \mathrm{v} / \mathrm{v} / \mathrm{min}$, with $\mathrm{CO}_{2}$ injected on demand at $\mathrm{pH}=8$. Eight $28 \mathrm{~W}$ fluorescent tubes (Philips Daylight T5) were used to artificially illuminated the reactors, in order to simulate daylight cycle. The cultures' temperature was kept at $25{ }^{\circ} \mathrm{C}$. The reactors were operated in batch mode for 6 days, after which they were operated in a semi-continuous mode $(20 \%)$ (i.e., every morning a $20 \%$ of the volume of each reactor volume was harvested during approximately $3 \mathrm{~h}$, while an equal volume of medium was introduced during the same time interval).

\subsubsection{Samples from stirred-tank reactors fed with sewage}

Experiments were performed in four $1 \mathrm{~L}$ stirred-tank reactors $(9 \mathrm{~cm}$ in diameter, $30 \mathrm{~cm}$ in height and with a $1.5 \mathrm{~L}$ capacity) operated in the laboratory but simulating outdoor conditions. These reactors were filled with $1 \mathrm{~L}$ of sewage taken directly after primary treatment from the wastewater treatment plant in Roquetas de Mar (Almería) and $20 \%$ of Scenedesmus almeriensis inoculum. To prevent the adverse effect of excessive dissolved oxygen accumulation, the dissolved oxygen was controlled and kept below $200 \%$ Sat by supplying air on demand; $\mathrm{CO}_{2}$ was also injected on demand to control the $\mathrm{pH}$ at 8 . The reactors were artificially illuminated using eight $28 \mathrm{~W}$ fluorescent tubes (Philips Daylight T5) on a simulated daylight cycle. The cultures' temperature was kept at $25^{\circ} \mathrm{C}$. The reactors were operated in batch mode for 6 days, after which they were operated in continuous mode. For this, $20 \%$ of culture volume was harvested every day and replaced with fresh culture medium.

\subsubsection{Samples from an outdoor raceway reactor fed with sewage}

A $32 \mathrm{~m}^{2}\left(4.4 \mathrm{~m}^{3}\right)$ open raceway reactor operated at a $0.12 \mathrm{~m}$ water depth was used. The reactor is equipped with a $1 \mathrm{~m}^{3}$ sump where $\mathrm{pH}$ is controlled at 8 . In the raceway reactor, the culture is circulated at $0.2 \mathrm{~m} \mathrm{~s}^{-1}$ using a rotating paddlewheel actuated by an electric motor [20]. A SCADA system monitors and controls the reactor's overall operation, including environmental parameters such as solar radiation and ambient temperature, and culture parameters such as $\mathrm{pH}$, temperature and dissolved oxygen. The experiments were performed in semi-continuous mode, by initially filling the reactor with wastewater inoculated with $10 \%$ total volume of Scenedesmus almeriensis culture, which was operated in batch mode for one week, after which it was operated in semi-continuous mode at a daily dilution rate of $20 \%$.

\subsubsection{Samples from an outdoor thin-layer cascade reactor fed with diluted manure}

An open $32 \mathrm{~m}^{2}\left(1.4 \mathrm{~m}^{3}\right)$ thin-layer cascade reactor operated at a $0.02 \mathrm{~m}$ water depth was used. The reactor is equipped with a $0.8 \mathrm{~m}^{3}$ sump where $\mathrm{pH}$ is controlled at 8 by the on-demand injection of pure $\mathrm{CO}_{2}$ at $51 \mathrm{~min}^{-1}$, or air supplied at $501 \mathrm{~min}^{-1}$ to remove oxygen [20]. A SCADA system monitors and controls the reactor's overall operation, including environmental parameters such as solar radiation and ambient temperature, and culture parameters. The experiments were performed in semi-continuous mode by initially filling the reactor with pig manure diluted in water (10\% pig manure, $90 \%$ water) and inoculated with a $10 \%$ total volume of Scenedesmus almeriensis culture from a $3.0 \mathrm{~m}^{3}$ tubular photobioreactor, which was operated in batch mode for one week, after which it was operated in semi-continuous mode at a daily dilution rate of $30 \%$.

\subsubsection{Samples from an outdoor tubular photobioreactor fed with fertilizers}

A $3.0 \mathrm{~m}^{3}$ capacity industrial tubular photobioreactor (T-PBR) was used for the $S$. almeriensis culture. The facility consists of ten tubular fence-type photobioreactors built as previously described [21]. The reactors were bubbled at a constant airflow rate of $2001 \cdot \mathrm{min}^{-1}$ while the $\mathrm{pH}$ is controlled $(\mathrm{pH}=8)$ by the on-demand injection of pure $\mathrm{CO}_{2}$ at $31 \mathrm{~min}^{-1}$. The culture temperature was controlled by passing cooling water. The reactors were operated in continuous mode by harvesting $20 \%$ of the culture volume every day, which was replaced by fresh medium.

\subsection{Biomass concentration and analytical methods}

The biomass concentration $(\mathrm{Cb})$ was measured by dry weight. The biomass concentration includes both microalgae, bacteria and inert suspended particles. It was used $100 \mathrm{~mL}$ aliquots of the culture filtered through Macherey-Nagel glass fiber MN 85/90. Then, the filters were dried in an oven at $80^{\circ} \mathrm{C}$ for $24 \mathrm{~h}$. Standard official methods approved by the Spanish Ministry of Agriculture [22] were used to check that the samples used were in starvation. Furthermore, the same methods were applied to analyse the composition of the wastewater samples and the water from the reactors. The phosphorus was measured by visible spectrophotometry through the phospho-vanado-molybdate complex. Nitrates were quantified at between 220 and $275 \mathrm{~nm}$ using a spectrophotometer. Ammonium was measured using the Nessler reactive method. The Total Chemical Oxygen Demand (COD) was determined by spectrophotometric measurement using Hach-Lange kits (LCl-400).

\subsection{Software and statistical analysis}

The data acquisition and control software DaqFactory (Azeotech, USA) was used to gather the photosynthesis and respiration rate data. All the experiments were performed at least by triplicate to allow calculating the mean values and standard deviation that are shown. Statistical analysis of data was carried out with the software Microsoft Excel.

\section{Results and discussion}

\subsection{Development of the proposed methodology}

To carry out the photo-respirometry methodology it was necessary to subject previously the culture samples to starvation to eliminate ammonium and organic matter. Then it is possible to add specific substrates that allow distinguishing between the respiration rates of the two types of bacteria studied. Heterotrophic biomass uses substrate consisting of carbonaceous material; therefore, it was checked for the absence of organic matter in the samples after starvation. Nitrifying bacteria, on the other hand, are autotrophic bacteria which use dissolved carbon dioxide to oxidise ammonia to nitrite and nitrite to nitrate. Thus, starvation is also applied in order to eliminate the initial ammonium in the culture. Then the addition of ammonium chloride is used to distinguish the nitrifying activity [23] of the sample. It was experimentally determined that one day of starvation is sufficient for primary domestic wastewater, two days for animal manure wastewater while three days are needed for lixiviated compost wastewater. After the starvation period, different respirometric measurements were performed using microalgae-bacteria cultures obtained from wastewater to check the viability of the methodology. A preliminary example of one functional test is shown in Table 2. It summarizes the overall values determined and the standard deviation of the measurements. It is possible to observe that during the light phase, the dissolved oxygen level increased rapidly from $100 \%$ Sat to $110 \%$ Sat.; the OPR was 16.7

Table 2

Results obtained in preliminary tests showing the method precision.

\begin{tabular}{|c|c|}
\hline Parameters & Rates \\
\hline $\mathrm{OPR}, \mathrm{mgO}_{2} / \mathrm{L} \cdot \mathrm{h}$ & $16.7 \pm 1.1$ \\
\hline $\mathrm{OCR}, \mathrm{mg} \mathrm{O} / 2 / \mathrm{L}$ & $-1.9 \pm 0.2$ \\
\hline MNPR, mgO $_{2} /$ gbiomass'h & $37.9 \pm 1.5$ \\
\hline HBRR, mg $\mathrm{O}_{2} /$ gbiomass $\cdot h$ & $-11.5 \pm 1.3$ \\
\hline $\mathrm{NBRR}, \mathrm{mg} \mathrm{O}_{2} /$ gbiomass $\cdot \mathrm{h}$ & $-7.2 \pm 0.6$ \\
\hline
\end{tabular}

Values correspond to the mean $\pm \operatorname{SD}(n=4)$. 
$\mathrm{mgO}_{2} / \mathrm{L} \cdot \mathrm{h}$. During the dark phase, the dissolved oxygen level dropped to $98 \%$ Sat; the OCR was $1.9 \mathrm{mgO}_{2} / \mathrm{L} \cdot \mathrm{h}$. From these values, it was calculated that the microalgae net photosynthesis rate (MNPR) was $37.9 \mathrm{mgO}_{2} /$ gbiomass $\mathrm{h}$, a value normalized to the biomass dry weight. Another sample of culture was used to determine the heterotrophic bacteria respiration rate (HBRR), which was calculated by adding sodium acetate to the sample after starvation. In this case, the dissolved oxygen level decreased to $93.9 \%$ Sat., resulting in a HBRR of 11.5 $\mathrm{mgO}_{2} /$ gbiomass h. Lastly, the nitrifying activity was determined by adding ammonium chloride as the nitrogen source. In these experiments the dissolved oxygen concentration during the dark phase dropped to $96.9 \%$ Sat., corresponding to an NBRR of $7.2 \mathrm{mgO}_{2} /$ gbiomass.h. The results confirm the precision of the measurements, with the standard deviation being less than $10 \%$ of the values obtained.

The results reported here show that a respirometry method based on oxygen production/consumption is a useful and rapid technique. This permitted to study the contribution of each population in the microalgae-bacteria consortium by distinguishing the oxygen production rate (OPR) from microalgae photosynthetic activity, the oxygen consumption rate (OCR) from endogenous respiration, the microalgae net photosynthesis rate (MNPR), the heterotrophic bacteria respiration rate (HBRR), and the nitrifying bacteria respiration rate (NBRR). The results from these preliminary tests, and its variability, were comparable to previous studies focusing on the activity of microalgal-bacterial wastewater consortia using respirometric tests. The oxygen consumption rate (OCR) results from endogenous respiration ( $3.8 \mathrm{mgO} / \mathrm{gbiomass} \cdot \mathrm{h}$ ) were quite similar to the results described by [17] of 4.3 and $4.1 \mathrm{mg}$ O2/gTSS.h, and were within the range indicated by [24] $(0.9-5.1 \mathrm{mg}$ O2/gTSS).

\subsection{Determination of optimum light availability and biomass concentration}

One of the main factors influencing microalgae behaviour is light availability, this is the irradiance to which the cells are exposed in the culture. This is determined by the external irradiance and the biomass concentration as well as the culture geometry and size (diameter in our case). To determine the optimal irradiance to carry out the measurements, experiments were performed using samples from laboratory stirred-tank reactors fed with sewage. These samples were selected because they are the most relevant in terms of the further application of the methodology proposed. The experiments were carried out at a fixed biomass concentration of $0.5 \mathrm{~g} / \mathrm{L}$, the irradiance inside the sample, measured with the interior sensor, was modified by changing the external irradiance. The results show that, at low irradiance values ( $50 \mu \mathrm{mol}$ photons $/ \mathrm{m}^{2} \cdot \mathrm{s}$ ), the microalgae photosynthesis rate is also low, increasing with light availability up to values of $500 \mu \mathrm{mol}$ photons/ $\mathrm{m}^{2} \cdot \mathrm{s}$, and then remaining constant up to values of $2000 \mu \mathrm{mol}$ photons/ $\mathrm{m}^{2} \cdot \mathrm{s}$ (Fig. 2). Regarding the heterotrophic and nitrifying bacteria, they did not show significant differences regardless of the irradiance values imposed. Microalgae activity, on the other hand, was maximal at values of $500 \mu \mathrm{mol}$ photons $/ \mathrm{m}^{2}$.s but to avoid saturation during photosynthesis, an irradiance of $200 \mu \mathrm{mol}$ photons $/ \mathrm{m}^{2}$.s was selected for the measurements. As with the previews studies, the results have verified that under real conditions, the cultures are mainly photo-limited, the average irradiance being from 100 to $300 \mu \mathrm{mol}$ photons $/ \mathrm{m}^{2} \cdot \mathrm{s}$ $[15,25,26]$. Regarding the biomass concentration, there is a direct relationship between the production/uptake of oxygen and the relative biomass concentration in the cultures. For this reason, determining the optimal biomass concentration at which the measurements should be performed was essential. This variable greatly impacts the method's precision and sensitivity. Consequently, experiments were also performed using microalgae cultures from laboratory stirred-tank reactors fed with sewage as the most representative sample type, with distilled water as the control. Measurements were carried out at different biomass concentrations up to $0.8 \mathrm{~g} / \mathrm{L}$, determining the three main metabolisms: (i) photosynthesis by microalgae, (ii) respiration by heterotrophic bacteria and (iii) respiration by nitrifying bacteria (Fig. 3). The results show that even for low biomass concentration values, as low as $0.1 \mathrm{~g} / \mathrm{L}$, the photosynthesis rate was high enough to provide a statistically significant response, much larger than the measurements' standard deviation. The oxygen production rate's standard deviation, based on the photosynthesis rate, was similar for every biomass concentration tested, so values from 0.1 to $0.8 \mathrm{~g} / \mathrm{L}$ can be used for the standard method. However, the oxygen consumption rate from the respiration measured was much lower than from photosynthesis; hardly measurable at biomass concentrations of $0.1 \mathrm{~g} / \mathrm{L}$. Only at a biomass concentrations of $0.2 \mathrm{~g} / \mathrm{L}$ there was a measurable oxygen consumption rate for bacteria but too close to the measurement error, so we decided to choose a biomass concentration of $0.5 \mathrm{~g} / \mathrm{L}$ and not higher to prevent severe light attenuation effects and because most samples are obtained with a concentration close to $0.5 \mathrm{~g} / \mathrm{L}$.

\subsection{Determination of mixotrophic activity}

In the literature, results about mixotrophic metabolism in microalgae-bacteria culture are ambiguous. Mixotrophic activity in microalgae is relevant because it could significantly affect the oxygen production and consumption rate, especially when carbonaceous substrates such as sodium acetate are used. Accordingly, some experiments were designed to evaluate the potential mixotrophic metabolism of microalgae in order to ensure that sodium acetate is consumed by heterotrophic bacteria when it is used as a substrate in respirometric tests.

On the one hand, samples from an outdoor raceway reactor fed with sewage were taken and the heterotrophic activity was evaluated following the proposed respirometric methodology. To ensure that this activity was due to the heterotrophic biomass and not to the microalgae activity of the wastewater culture, samples of the same culture were filtered through $0,9 \mu \mathrm{m}$ fiber filters to separate the biomass from the liquid phase.

Then, the heterotrophic activity of the filtrate was evaluated by respirometric tests. The results showed that heterotrophic activity in microalgae wastewater samples was $2.3 \mathrm{mgO}_{2} / \mathrm{L} \cdot \mathrm{h}$ while $2.1 \mathrm{mgO}_{2} / \mathrm{L} \cdot \mathrm{h}$ was the heterotrophic activity in the liquid phase using acetate as a substrate (Fig. 4). This experiment was essential to ensure that the mixotrophic behaviour of the microalgae can be neglected because the heterotrophic activity was the same with or without microalgae, being this activity caused by the heterotrophic biomass from the wastewater. The small difference between the two measurements could be due to the heterotrophic biomass that is retained in the filter along with the microalgae.

Once the mixotrophic activity in wastewater cultures has been discarded, the possible mixotrophic growth of Scenedesmus almeriensis cultures using sodium acetate as an organic substrate has been studied. In this way, the methodology described in section "2.4.2 Samples from spherical flasks fed with Arnon medium with acetate" was applied.

The results show that the growth of Scenedesmus almeriensis is the same under photoautotrophic conditions and using $0.005 \mathrm{M}, 0.01 \mathrm{M}$ and $0.05 \mathrm{M}$ sodium acetate (data not shown). In this sense, it can be ruled out that Scenedesmus almeriensis uses sodium acetate for its growth. These data demonstrate that the main microalgae presents in the cultures does not use sodium acetate in the short term. This results allowed discarding the influence of sodium acetate consumption during respirometric tests, although the possibility that they were capable of using acetate for mixotrophic growth in the long term cannot be ruled out, but in any case it requires a long adaptation time or it is only consumed under conditions of strong light limitation [27].

\subsection{Evaluation of the metabolisms prevailing in different cultures}

Once the methodology was defined, it could be used to evaluate the metabolism in different samples from different culture media and reactors (both in the laboratory and outdoors) (Table 1). The results show 


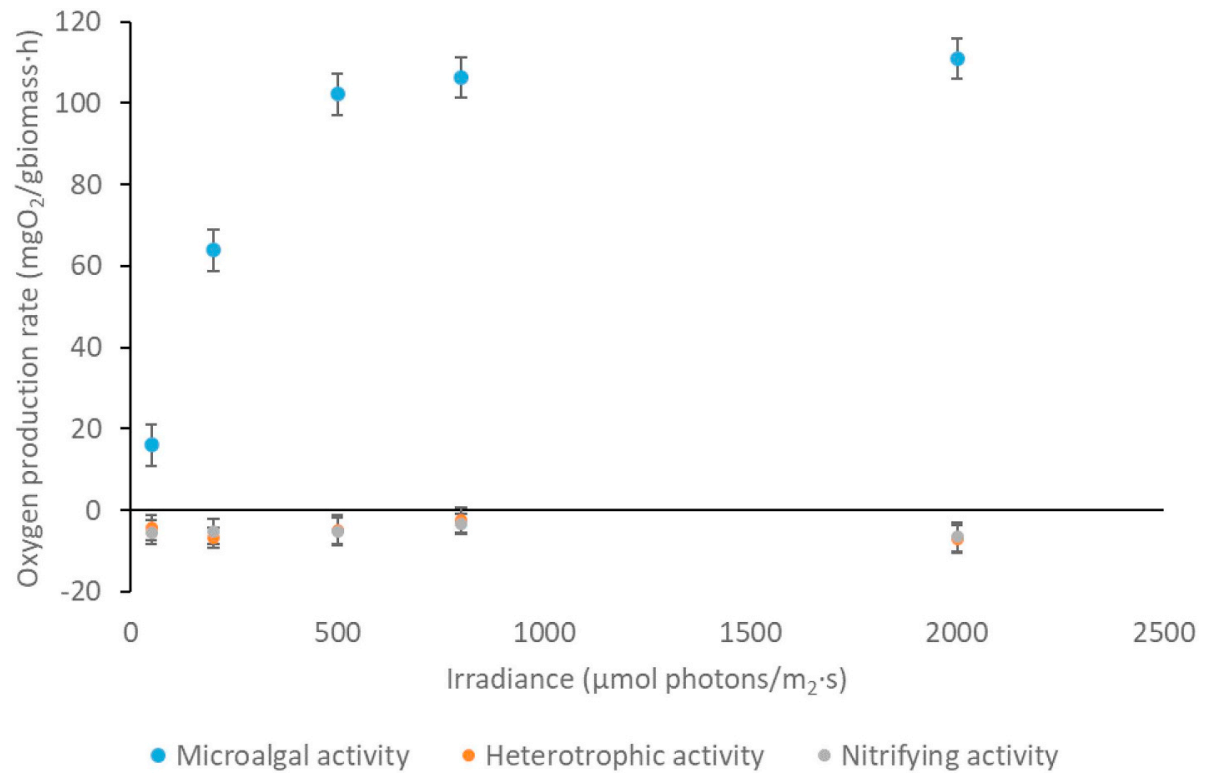

Fig. 2. Influence of irradiance on the different net metabolisms considered: microalgal activity, heterotrophic activity and nitrifying activity. Values correspond to the mean \pm SD $(n=3)$.

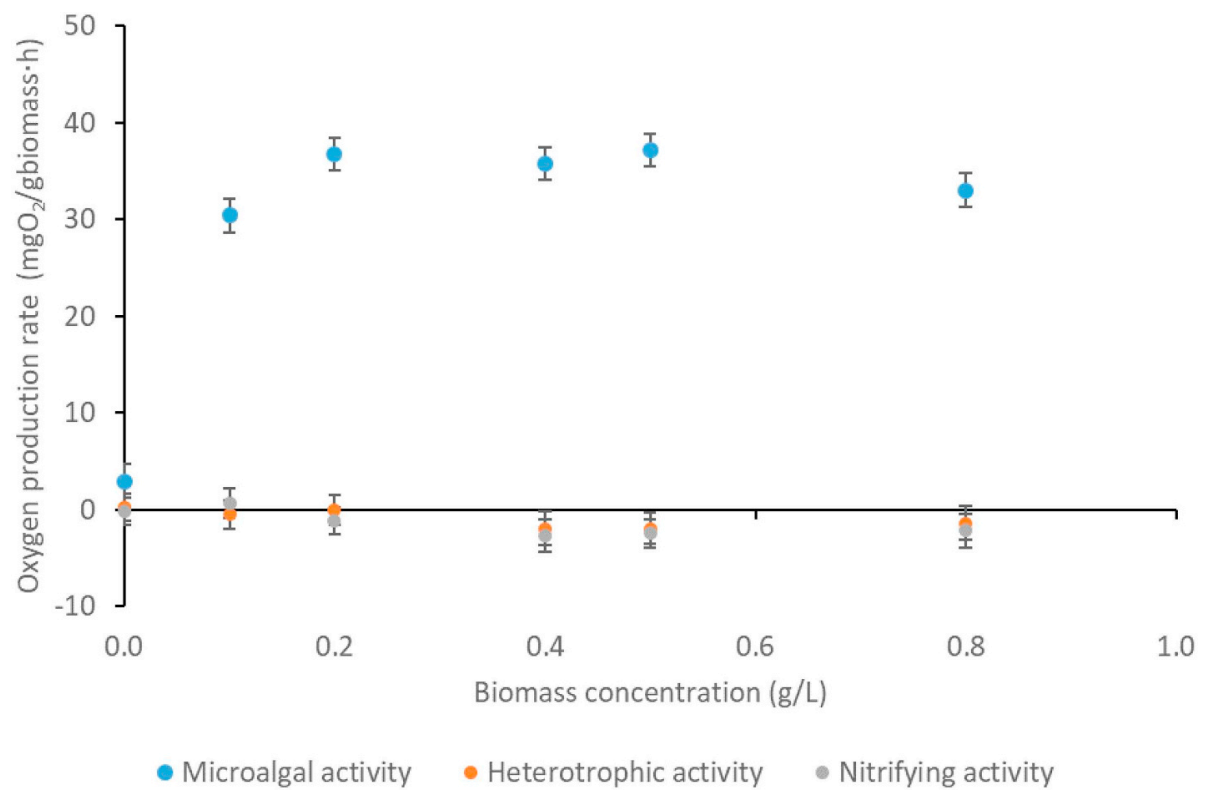

Fig. 3. Influence of biomass concentration on the different metabolisms considered: microalgal activity, heterotrophic activity and nitrifying activity. Values correspond to the mean $\pm \mathrm{SD}(\mathrm{n}=3)$.

that the oxygen production rate from photosynthesis was higher than the heterotrophic and nitrifying activity in all cases, with maximal values being obtained from pure microalgae cultures (Fig. 5); especially in $S$. almeriensis culture from spherical flasks ( $\left.129 \mathrm{mgO}_{2} / \mathrm{gbiomass} \cdot \mathrm{h}\right)$. The microalgae net photosynthetic activity from $S$. almeriensis in bubble columns was comparable to the activity in spherical flasks (118.9 $\mathrm{mgO}_{2}$ /gbiomass.h). The photosynthetic activity of $S$. almeriensis in the tubular photobioreactor was likewise very similar to that in culture produced using animal manure in a thin-layer reactor (94.3 and 92.5 $\mathrm{mgO}_{2} /$ gbiomass h, respectively). These results suggest that using pig manure as the microalgae substrate is an excellent alternative method for treating animal manure and producing microalgae biomass. Although the most common way of reusing pig manure is to spread it on farmland, some authors have described how it can be used to produce microalgae biomass $[28,29]$. Not only have we been able to demonstrate that pig manure serves as a good microalgae substrate, but the data also show the high microalgae activity achieved from using agricultural leachate wastes as the substrate, with a microalgae activity of $56.1 \mathrm{mgO}_{2} /$ gbiomassh. In the outdoor raceway reactor using primary domestic wastewater, microalgae activity was lower $\left(37.8 \mathrm{mgO}_{2} /\right.$ gbiomass.h), similar to that achieved using the laboratory-scale photobioreactor ( $34.3 \mathrm{mgO}_{2} /$ gbiomass'h) As previous studies reported, this was possible because the thin-layer reactor was more photosynthetically efficient at producing Scenedesmus sp. than the raceway reactor and the closed tubular photobioreactor [20,30].

Heterotrophic activity in the activated sludge treatment process has been studied and described for decades because it is responsible for oxidizing the organic material and is capable of forming flocs, which also facilitate effluent clearing [31]. Accordingly, it is necessary to determine the heterotrophic population which appears in microalgaebacteria consortia wastewater treatment. Our results show that heterotrophic activity was very similar in vegetal compost leachate culture 


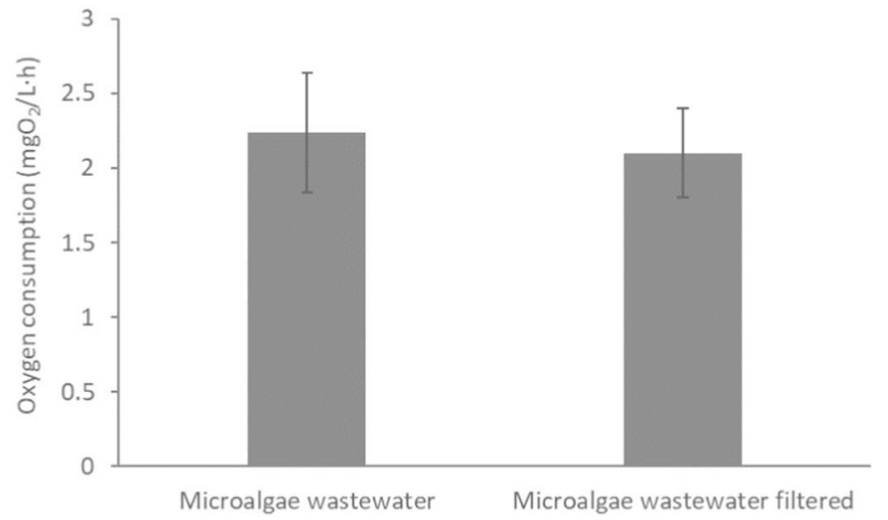

Fig. 4. Influence of microalgae presence in the oxygen consumption by heterotrophic bacteria when sodium acetate was used as a substrate. Values correspond to the mean $\pm \operatorname{SD}(n=3)$.

(8.9 $\mathrm{mg} \mathrm{O} \mathrm{O}_{2} /$ gbiomass.h) and animal manure culture $(7.6 \mathrm{mg} \mathrm{O} /$ gbiomass.h), corresponding to the highest heterotrophic activity values measured. These results were in agreement with the chemical oxygen demand (COD) values recorded in animal manure and compost leachate, corresponding to $20.200 \mathrm{mg} / \mathrm{L}$ and $33.200 \mathrm{mg} / \mathrm{L}$, respectively. The results from the two systems using primary domestic wastewater were comparable, showing that heterotrophic activity was present at a similar level, though slightly lower in the raceway reactor $\left(2.6 \mathrm{mg} \mathrm{O}_{2}\right.$ / gbiomass.h) than in the laboratory reactors ( $4 \mathrm{mg} \mathrm{O}_{2} /$ gbiomass.h). The respiration rate using $S$. almeriensis culture in the pilot column system (3.8 $\mathrm{mgO}_{2} /$ gbiomass.h) and in the tubular cultures $\left(3.7 \mathrm{mgO}_{2} /\right.$ gbiomass.h) was similar to that obtained from wastewater, indicating that organic matter removal from wastewater treatment using microalgae was quite efficient. The heterotrophic activity measured in the laboratory cultures ( $2.3 \mathrm{mgO}_{2} /$ gbiomass) was the expected response because preview studies have described that most microalgae culture collections exist in a non-axenic state because other organisms, such as bacteria and microfungi, are present in the culture due to co-insolation [32].

Regarding the experimental measurement of the nitrifying activity, after the starvation period, it was necessary to check that the nitrogen

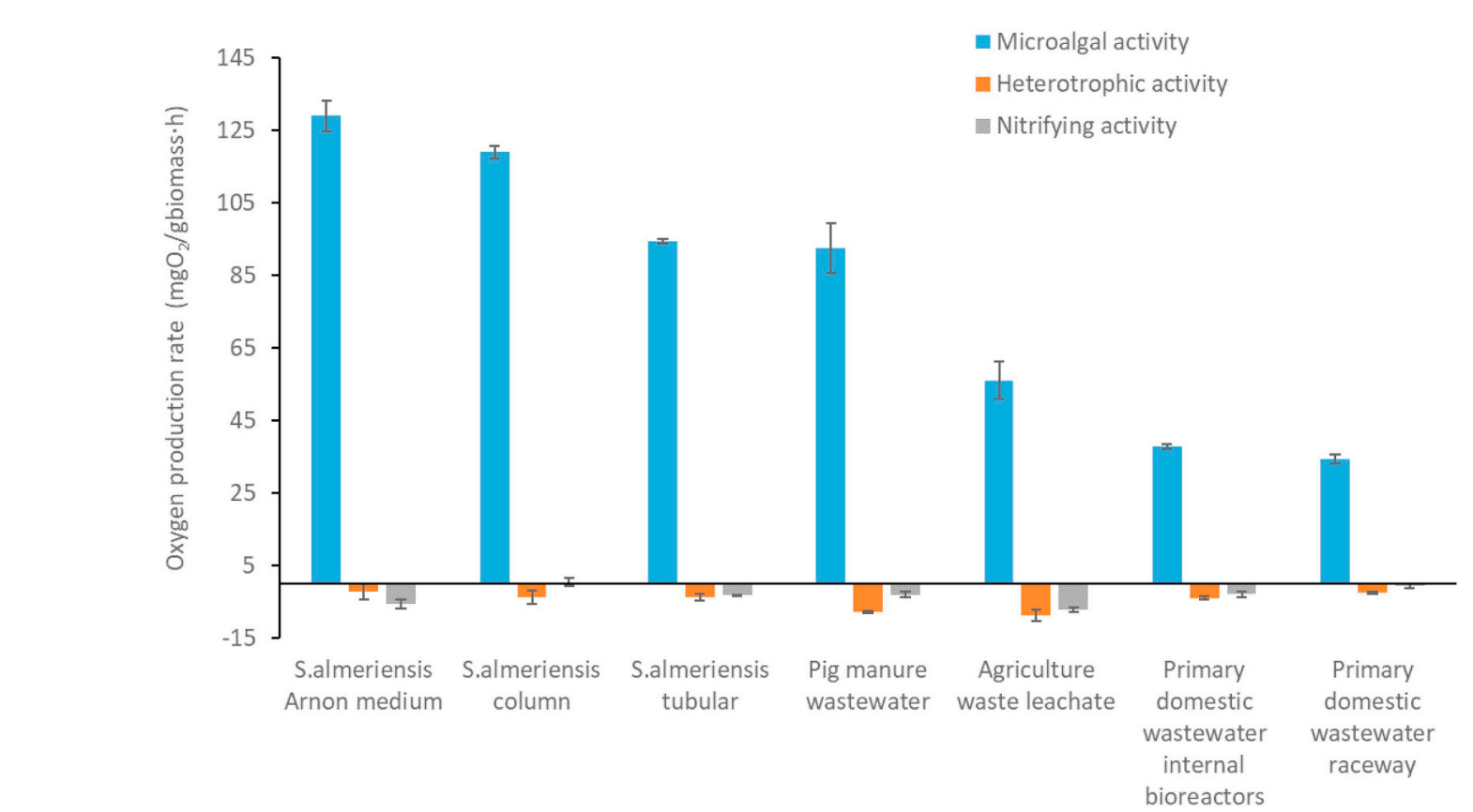

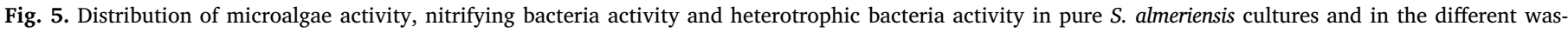

tewaters used. Values correspond to the mean $\pm \operatorname{SD}(n=4)$. remaining in the cultures in the form of ammonium was below $2 \mathrm{mg} \cdot \mathrm{L}^{-1}$. The results showed that maximal nitrifying activity was obtained using leachate from crop residues as the culture media (8.4 $\mathrm{mgO}_{2}$ /gbiomass $\mathrm{h}$ ). These results were supported by previous studies on agricultural waste composting, which described the presence of ammonia-oxidizing archaea and bacteria; these transform $\mathrm{NH}_{3}$ to $\mathrm{NO}^{-3}$ during nitrification. [33]. The nitrifying activity measured in S. almeriensis laboratory cultures was $5.6 \mathrm{mgO}_{2}$ /gbiomass $\mathrm{h}$, higher than the nitrifying activity measured when different types of wastewater were tubular reactors ( $3.2 \mathrm{mgO}_{2}$ /gbiomass.h). A similar value was obtained when animal manure was used as the substrate ( $3 \mathrm{mgO} / \mathrm{gbiomass} \cdot \mathrm{h})$. Nitrification in samples obtained from microalgae cultures grown in animal manure have been reported by some authors; this is because nitrogen in the form of ammonia nitrogen is present at very high concentrations in animal manures such as pig waste [34,35], with ammonium comprising up to $70 \%$ of the nitrogen present in liquid manure [36]. The animal manure used in this study contained up to $3.1 \mathrm{~g} \mathrm{NH}_{4} / \mathrm{L}$ and it was diluted to $10 \%$ for use in the microalgae cultures. The results for the two systems using primary domestic wastewater were comparable although they show that nitrifying activity was present at a slightly higher level in the laboratory reactors $\left(2.9 \mathrm{mg} \mathrm{O}_{2} /\right.$ gbiomass.h) than in the external raceway $\left(0.6 \mathrm{mg} \mathrm{O}_{2} /\right.$ gbiomass.h), with both primary domestic wastewaters containing a low ammonium concentration $(70 \mathrm{mg}$ / L) diluted by $20-10 \%$, respectively.

\subsection{Further improvements of the methodology}

After standardizing the proposed respirometric method and protocol, the method needed to be further improved in certain aspects such as finding specific nitrifying inhibitors to help discriminating microalgae activity and activity from nitrifying bacteria when ammonium chloride is used as a substrate. In this regard, tests have been carried out using allylthiourea (ATU) solution, known to cause the inhibition of ammonia-oxidizing bacteria (AOB) in the respirometric tests, in order to definitively discriminate between ammonium consumption by nitrifying activity and by microalgae activity. In this way, the methodology described in Section 2.3, "Respiration rate measurements inhibiting nitrifying activity", was applied using samples from an outdoor used. The nitrifying activity was also measured for $S$. almeriensis in 


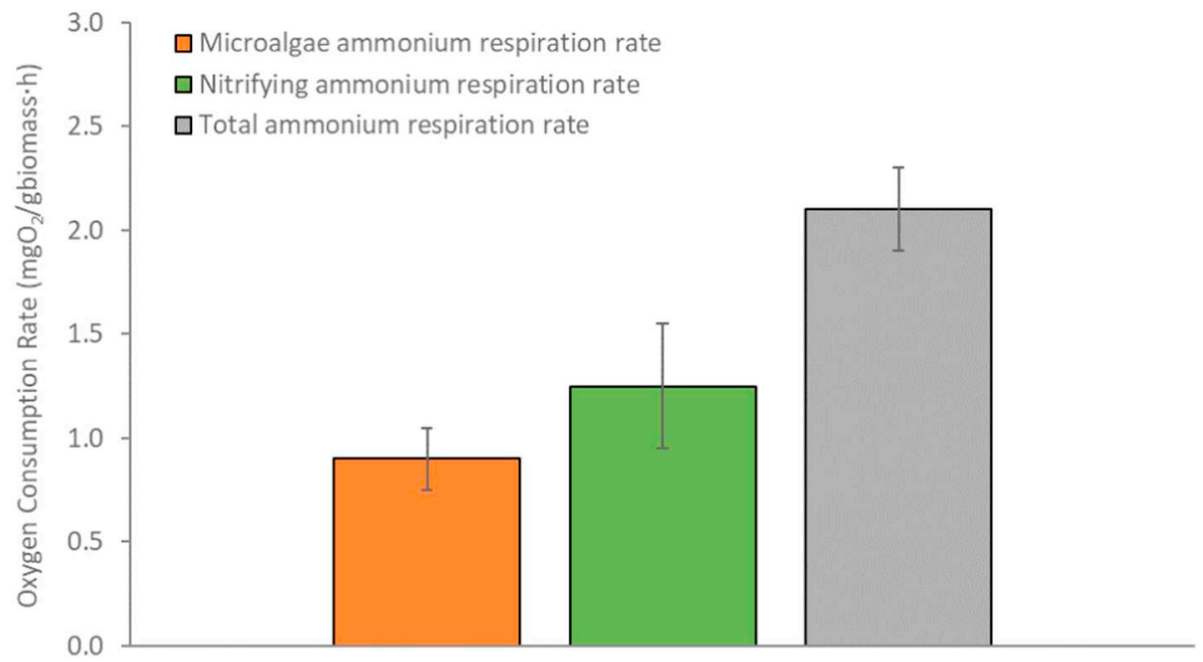

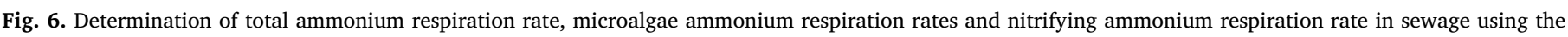
respirometric protocol with ATU as inhibitor solution. Values correspond to the mean \pm SD $(n=3)$.

raceway reactor fed with sewage. These tests showed a total ammonium respiration rate when using ammonium chloride as a substrate of 2.1 $\mathrm{mgO}_{2} /$ gbiomass $h$, being the respiration of the nitrifying ammonium respiration rate of $1.2 \mathrm{mgO}_{2} / \mathrm{gbiomass} h$ and the microalgae ammonium respiration rate of $0.9 \mathrm{mgO}_{2} /$ gbiomass h (when ATU is applied) (Fig. 6). This methodology is consistent with the one proposed by [17], and helps to optimize and improve respirometric techniques to study the main microbiological metabolisms in wastewater treatment. These results suggested that it is necessary to carry out some tests with ATU before applying the methodology in order to ensure what ammonium percentage is consumed by nitrifying bacteria.

\section{Conclusions}

The photo-respirometry method developed allows quantifying the contribution of the three main microorganism types that appear in wastewater treatment: microalgae, heterotrophic bacteria and nitrifying bacteria in term of oxygen production and oxygen consumption. The correct application of the proposed methodology was due to the standardization of the photo-respirometry method, including the starvation period required, the established protocol, the substrates and inhibitors applied the biomass concentration and irradiance during the measurements, etc. The method has been applied to microalgae/bacteria consortia established in different wastewater treatment systems (different reactors, water types and operating conditions). The data confirm that in respirometric term, microalgae are the main microorganisms contributing to the microalgae-bacteria consortia, heterotrophic bacteria maintain a relatively stable activity whatever the operational conditions whereas the nitrifying bacteria activity largely depends on the nitrogen load and the microalgae activity. This method is a powerful tool for improving the performance of microalgae-based wastewater treatment processes, for obtaining kinetic parameters of microalgae and bacteria and, even so, for studying the complex relationship between microalgae and nitrifying bacteria.

\section{CRediT authorship contribution statement}

A. Sánchez-Zurano: Conceptualization, Methodology, Software, Formal analysis, Investigation, Writing - original draft. C. GómezSerrano: Validation, Resources, Supervision. F.G. Acién-Fernández: Supervision, Writing - review \& editing, Funding acquisition. J.M. Fernández-Sevilla: Project administration, Funding acquisition, Writing - review \& editing. E. Molina-Grima: Writing - review \& editing, Funding acquisition.

\section{Declaration of competing interest}

The authors declare that they have no known competing financial interests or personal relationships that could have appeared to influence the work reported in this paper.

\section{Acknowledgements}

This research was funded by the SABANA project (grant \# 727874) of the European Union's Horizon 2020 Research and Innovation Programme, by the PURASOL project CTQ2017-84006-C3-3-R (Ministerio de Economía y Competitividad, Gobierno de España) as well as being supported by the Marine Microalgal Biotechnology group (BIO 173) in the Chemical Engineering Department, University of Almeria, Spain, Fundación Cajamar and the Spanish Ministry of Education through the National FPU Programme (grant number FPU16/05996).

\section{Statement of informed consent, human/animal rights}

No conflicts, informed consent, human or animal rights applicable to this study.

\section{References}

[1] J. Fuentes, I. Garbayo, M. Cuaresma, Z. Montero, M. González-del-Valle, C. Vílchez, Impact of microalgae-bacteria interactions on the production of algal biomass and associated compounds, Mar. Drugs. 14 (2016) 100, https://doi.org/10.3390/ md14050100.

[2] C. Gómez-Serrano, M.M. Morales-Amaral, F.G. Acién, R. Escudero, J.M. FernándezSevilla, E. Molina-Grima, Utilization of secondary-treated wastewater for the production of freshwater microalgae, Appl. Microbiol. Biotechnol. 99 (2015) 6931-6944, https://doi.org/10.1007/s00253-015-6694-y.

[3] R. Muñoz, B. Guieysse, Algal-bacterial processes for the treatment of hazardous contaminants: a review, Water Res. 40 (2006) 2799-2815, https://doi.org/10. 1016/j.watres.2006.06.011.

[4] E.J. Olguín, Dual purpose microalgae-bacteria-based systems that treat wastewater and produce biodiesel and chemical products within a biorefinery, Biotechnol. Adv. 30 (2012) 1031-1046.

[5] S. Petrini, P. Foladori, G. Andreottola, Laboratory-scale investigation on the role of microalgae towards a sustainable treatment of real municipal wastewater, Water Sci. Technol. 78 (2018) 1726-1732, https://doi.org/10.2166/wst.2018.453.

[6] G. Quijano, J.S. Arcila, G. Buitrón, Microalgal-bacterial aggregates: applications and perspectives for wastewater treatment, Biotechnol. Adv. 35 (2017) 772-781, https://doi.org/10.1016/j.biotechadv.2017.07.003.

[7] R. Muñoz, C. Köllner, B. Guieysse, Biofilm photobioreactors for the treatment of industrial wastewaters, J. Hazard. Mater. 161 (2009) 29-34, https://doi.org/10. 1016/j.jhazmat.2008.03.018.

[8] J. Zambrano, I. Krustok, E. Nehrenheim, B. Carlsson, A simple model for algaebacteria interaction in photo-bioreactors, Algal Res. 19 (2016) 155-161, https:// doi.org/10.1016/j.algal.2016.07.022. 
[9] I.T.D. Cabanelas, J. Ruiz, Z. Arbib, F.A. Chinalia, C. Garrido-Pérez, F. Rogalla, A. Nascimento, J.A. Perales, C. Garrido-P??rez, F. Rogalla, I.A. Nascimento, J.A. Perales, Comparing the use of different domestic wastewaters for coupling microalgal production and nutrient removal, Bioresour. Technol. 131 (2013) 429-436, https://doi.org/10.1016/j.biortech.2012.12.152.

[10] F.G. Acién, C. Gómez-Serrano, M.M. Morales-Amaral, J.M. Fernández-Sevilla, E. Molina-Grima, Wastewater treatment using microalgae: how realistic a contribution might it be to significant urban wastewater treatment? Appl. Microbiol. Biotechnol. 100 (2016) 9013-9022.

[11] B. Decostere, N. Janssens, A. Alvarado, T. Maere, P. Goethals, S.W.H. Van Hulle, I. Nopens, A combined respirometer-titrimeter for the determination of microalgae kinetics: experimental data collection and modelling, Chem. Eng. J. 222 (2013) 85-93, https://doi.org/10.1016/j.cej.2013.01.103.

[12] Z. Dubinsky, P.G. Falkowski, A.F. Post, U.M. van Hes, A system for measuring phytoplankton photosynthesis in a defined light field with an oxygen electrode, J. Plankton Res. 9 (1987) 607-612, https://doi.org/10.1093/plankt/9.4.607.

[13] E. Sforza, M. Pastore, E. Barbera, A. Bertucco, Respirometry as a tool to quantify kinetic parameters of microalgal mixotrophic growth, Bioprocess Biosyst. Eng. 42 (2019) 839-851, https://doi.org/10.1007/s00449-019-02087-9.

[14] T. Tang, H. Fadaei, Z. Hu, Rapid evaluation of algal and cyanobacterial activities through specific oxygen production rate measurement, Ecol. Eng. 73 (2014) 439-445, https://doi.org/10.1016/j.ecoleng.2014.09.095.

[15] T.A.A. Costache, F.G.A. Fernández, F.G. Acien, M.M. Morales, J.M. Fernández Sevilla, I. Stamatin, E. Molina, Comprehensive model of microalgae photosynthesis rate as a function of culture conditions in photobioreactors, Appl. Microbiol. Biotechnol. 97 (2013) 7627-7637.

[16] D. Ippoliti, C. Gómez, M.M. Morales-Amaral, R. Pistocchi, J.M.M. FernándezSevilla, F.G.G. Acién, Modeling of photosynthesis and respiration rate for Isochrysis galbana (T-Iso) and its influence on the production of this strain, Bioresour. Technol. 203 (2016) 71-79.

[17] S. Rossi, M. Bellucci, F. Marazzi, V. Mezzanotte, E. Ficara, Activity assessment of microalgal-bacterial consortia based on respirometric tests, Water Sci. Technol. J. Int. Assoc. Water Pollut. Res. 78 (2018) 207-215, https://doi.org/10.2166/wst. 2018.078.

[18] P.A. Vanrolleghem, Principles of Respirometry in Activated Sludge Wastewater Treatment, (2002)

[19] M.B. Allen, D.I. Arnon, Studies on nitrogen-fixing blue-green algae. I. Growth and nitrogen fixation by anabaena Cylindrica Lemm1, Plant Physiol. 30 (1955) 366-372.

[20] M. del M. Morales-Amaral, C. Gómez-Serrano, F.G. Acién, J.M. Fernández-Sevilla E. Molina-Grima, Outdoor production of Scenedesmus sp. in thin-layer and raceway reactors using centrate from anaerobic digestion as the sole nutrient source, Algal Res. 12 (2015) 99-108, https://doi.org/10.1016/j.algal.2015.08.020.

[21] I. Fernández, F.G.G. Acién, M. Berenguel, J.L.J.L.L. Guzmán, First principles model of a tubular photobioreactor for microalgal production, Ind. Eng. Chem. Res. 53
(2014) 11121-11136, https://doi.org/10.1021/ie501438r.

[22] Ministerio de Agricultura, Métodos Oficiales de Análisis: Suelos y Aguas, (1982).

[23] P.A. Vanrolleghem, Principles of Respirometry in Activated Sludge Wastewater Treatment, (n.d.) 20

[24] A. Ruiz-Martinez, J. Serralta, A. Seco, J. Ferrer, Behavior of mixed Chlorophyceae cultures under prolonged dark exposure. Respiration rate modeling, Ecol. Eng. 91 (2016) 265-269, https://doi.org/10.1016/j.ecoleng.2016.02.025.

[25] F.G. Acién Fernández, F. García Camacho, Y. Chisti, Photobioreactors: light regime, mass transfer, and scaleup, in: R. Osinga, J. Tramper, J.G. Burgess, R.H. Wijffels (Eds.), Prog. Ind. Microbiol, Elsevier, 1999, pp. 231-247, , https://doi.org/10. 1016/S0079-6352(99)80118-0.

[26] F.A. Fernández, F.G. Camacho, J.S. Pérez, J.F. Sevilla, E.M. Grima, Modeling of biomass productivity in tubular photobioreactors for microalgal cultures: effects of dilution rate, tube diameter, and solar irradiance, Biotechnol. Bioeng. 58 (1998) 605-616.

[27] M.C.C. Garcia, J.M.F. Sevilla, F.G.A. Fernandez, E.M. Grima, F.G. Camacho, F, Mixotrophic growth of Phaeodactylum tricornutum on glycerol: growth rate and fatty acid profile, J. Appl. Phycol. 12 (2000) 239-248.

[28] A. Bai, L. Stündl, P. Bársony, M. Fehér, P. Jobbágy, Z. Herpergel, G. Vaszkó, Algae production on pig sludge, Agron. Sustain. Dev. 32 (2012) 611-618, https://doi.org/ 10.1007/s13593-011-0077-2.

[29] M. Wilson, J.A. Houghton, Growth of algae on pig manure, Ir. J. Agric. Res. 13 (1974) 49-60.

[30] F.G. Acién, J.M. Fernández, J.J. Magán, E. Molina, Production cost of a real microalgae production plant and strategies to reduce it, Biotechnol. Adv. 30 (2012) 1344-1353.

[31] C.G. Gayford, J.P. Richards, Isolation and enumeration of aerobic heterotrophic bacteria in activated sludge, J. Appl. Bacteriol. 33 (1970) 342-350, https://doi.org/ 10.1111/j.1365-2672.1970.tb02205.x.

[32] R. Amaral, J.C. Pereira, A.A.C.C. Pais, L.M.A. Santos, Is axenicity crucial to cryopreserve microalgae? Cryobiology 67 (2013) 312-320, https://doi.org/10.1016/j. cryobiol.2013.09.006.

[33] G. Zeng, J. Zhang, Y. Chen, Z. Yu, M. Yu, H. Li, Z. Liu, M. Chen, L. Lu, C. Hu, Relative contributions of archaea and bacteria to microbial ammonia oxidation differ under different conditions during agricultural waste composting, Bioresour. Technol. 102 (2011) 9026-9032, https://doi.org/10.1016/j.biortech.2011.07.076.

[34] M. Blouin, J.G. Bisaillon, R. Beaudet, M. Ishaque, Nitrification of swine waste, Can. J. Microbiol. 36 (1990) 273-278.

[35] M.R. Evans, M.P.W. Smith, E.A. Deans, I.F. Svoboda, F.E. Thacker, Nitrogen and aerobic treatment of slurry, Agric. Wastes. 15 (1986) 205-213, https://doi.org/10. 1016/0141-4607(86)90016-8.

[36] E. Baumgarten, M. Nagel, R. Tischner, Reduction of the nitrogen and carbon content in swine waste with algae and bacteria, Appl. Microbiol. Biotechnol. 52 (1999) 281-284, https://doi.org/10.1007/s002530051522. 